\title{
New Age-Linked Asymmetries: Aging and the Processing of Familiar Versus Novel Language on the Input Versus Output Side
}

\author{
Lori E. James \\ University of Colorado at Colorado Springs
}

\author{
Donald G. MacKay \\ University of California, Los Angeles
}

\begin{abstract}
This research demonstrates 3 new age-linked asymmetries between identifying versus retrieving phonological information. Young and older adults read aloud familiar isolated words (e.g., mind) and novel pseudowords (e.g., mond) in a production task and identified lexical status for identical stimuli in a comprehension task. Young adults made fewer errors than older adults in production but not comprehension (an age-related input-output asymmetry), and they produced pseudowords but not words with fewer errors than older adults (a lexical-status asymmetry). The lexical-status asymmetry also occurred for response onset times but not for output durations (an onset-output asymmetry). All 3 asymmetries were predicted under the transmission deficit hypothesis (D. G. MacKay \& D. M. Burke, 1990) but contradict theories such as general slowing that cannot explain why aging affects some types of information processing more than others.
\end{abstract}

Keywords: language production, language perception, pronunciation, lexical decision, aging

The input side of language involves perception and comprehension of letters and speech sounds, and comprehension of the meaning of words and sentences. The output side of language involves retrieval of lexical and phonological information during everyday language production and retrieval of orthographic information during everyday writing and typing. This input-output distinction may carry little empirical or theoretical significance if output-side processes simply mirror input-side processes. However, we begin by reviewing indications that aging may have asymmetric effects for input- versus output-side processing of phonological and lexical information: When age-linked deficits in sensory processing, encoding of new information, working memory, and rapid processing are controlled or factored out, input-side processes seem to remain remarkably stable in old age, whereas corresponding output-side processes exhibit dramatic declines (for reviews, see Burke \& MacKay, 1997; Kemper, 1992; Light, 1992; MacKay \& Abrams, 1996; Wingfield \& Stine-Morrow, 2000).

This asymmetric pattern, if not the result of experimental artifact, carries both empirical and theoretical significance: Empirically, input-output asymmetries suggest that aging affects outputside processes much more than input-side processes, and theoretically, input-output asymmetries suggest that input- and

Lori E. James, Department of Psychology, University of Colorado at Colorado Springs; Donald G. MacKay, Department of Psychology, University of California, Los Angeles.

Aspects of this research were presented at the 2002 Language Comprehension across the Life Span Conference, Kansas City, Missouri, and the 2006 Cognitive Aging Conference, Atlanta, Georgia. We thank Kethera Fogler, Laura Roth, and Crystal Trujillo for research assistance and Hasker Davis for assistance recruiting participants.

Correspondence concerning this article should be addressed to Lori E. James, Department of Psychology, University of Colorado at Colorado Springs, 1420 Austin Bluffs Parkway, Colorado Springs, CO 80933-7150. E-mail: ljames@uccs.edu output-side processes are not mirror images and that verbal abilities are not subject to across-the-board sparing or impairment, as is suggested in general slowing theories (e.g., Myerson, Hale, Wagstaff, Poon, \& Smith, 1990; Salthouse, 1996). The present study was designed to test predictions from prominent competing theories of cognition and aging while using ecologically valid tasks in which people often engage. Critically, the present study extends previous research by controlling for possible artifacts that have been identified in earlier experiments and by demonstrating two new types of age-linked production asymmetries.

\section{Asymmetric Effects of Aging on the Input Versus Output Side}

To illustrate age stability for lexical and phonological processes on the input side, consider the comprehension of isolated words in the semantic priming paradigm: Laver and Burke (1993) reviewed results of 15 semantic priming studies indicating that presenting a word (e.g., doctor) automatically spreads activation to related words (e.g., nurse) without deficit in old age (see also Laver, 2000). Sentence contexts also prime comprehension of word meanings to equivalent extents for young and older adults (e.g., Burke \& Yee, 1984; Stine \& Wingfield, 1994). Similarly, errors in lexical decision tasks do not differ for young versus older adults (Ferraro \& Moody, 1996), and vocabulary scores in tests such as the Wechsler Adult Intelligence Scale remain stable or improve with aging (e.g., Botwinick, 1984; Kramer \& Jarvik, 1979; see Verhaeghen, 2003, for a recent meta-analysis). Finally, age constancy occurs for both offline and online measures of word comprehension in sentences (e.g., Cohen \& Faulkner, 1983; Light, Valencia-Laver, \& Zavis, 1991; Madden, 1988; Speranza, Daneman, \& Schneider, 2000; Stine \& Wingfield, 1994; Wingfield, Alexander, \& Cavigelli, 1994; for a review, see Burke \& MacKay, 1997).

By contrast, the ability to retrieve or produce specific, wellknown words exhibits large age-linked declines (see Burke \& 
MacKay, 1997; MacKay \& Abrams, 1998, for reviews). For example, temporary inability to retrieve familiar words increases with aging in both diary studies (Burke, MacKay, Worthley, \& Wade, 1991; Heine, Ober, \& Shenault, 1999) and laboratory experiments (e.g., A. S. Brown \& Nix, 1996; Burke et al., 1991; James \& Burke, 2000; Maylor, 1990; White \& Abrams, 2002), and older adults consider this "tip-of-the-tongue" (TOT) phenomenon one of their most troublesome problems (e.g., Cohen \& Faulkner, 1986; Sunderland, Watts, Baddeley, \& Harris, 1986). Moreover, older adults experiencing TOTs during word production can report fewer phonological features of a target word, such as its stress pattern and initial phoneme, and have fewer phonologically similar words come spontaneously to mind than do young adults (e.g., Rastle \& Burke, 1996). Older adults are also less accurate and slower than young adults to produce names corresponding to definitions, pictures, and actions (e.g., Au et al., 1995; Bowles \& Poon, 1985; Feyereisen, 1997; Schmitter-Edgecombe, Veneski, \& Jones, 2000) and to produce a target word given its definition and initial letter, or given its initial letter and general semantic category (e.g., McCrae, Arenberg, \& Costa, 1987).

Age-linked deficits in word retrieval implicate access to phonological information because providing phonological cues to a TOT target reduces the age deficits (e.g., Mitchell, 1989), but providing additional semantic information does not (Bowles \& Poon, 1985). However, age-linked production deficits are not confined to phonological levels of language production. To illustrate, consider morphological speech errors, for example, the word pans misproduced as "pan" where the plural morpheme has been omitted: MacKay and James (2004) demonstrated an age-linked increase in phonological speech errors involving morphemes relative to ones not involving morphemes (e.g., pant misproduced as "pan”).

\section{Theoretical Issues Linked to Input-Output Asymmetries}

What explains the asymmetric age-linked effects in these separate studies of aging on the input versus output side? One possibility is experimental artifact: Participants and stimuli differed in the experiments reviewed above, and the comprehension tasks may have been "easier" than the production tasks. Because the previous results might be attributed to experimental artifact, one goal of the present experiment was to determine whether the effects of aging on comprehension and production are truly symmetric or equivalent in magnitude when appropriate controls are used.

In theoretical frameworks derived from theories in which comprehension and production processes are not mirror images, it is hypothesized that aging has disproportionately greater effects on language production than language comprehension. An example is the transmission deficit hypothesis (TDH), as embedded within node structure theory (e.g., Burke, MacKay, \& James, 2000; MacKay, 1987; MacKay \& Burke, 1990). We tested three separate age-linked asymmetries predicted under TDH and examined its mechanisms for comprehending versus producing lexical and phonological information in detail in the present study.

\section{TDH and the Input-Output Asymmetry}

Under TDH, verbal information is represented in a network of interconnected units or nodes organized into a semantic system representing lexical and propositional meaning, and a phonological system representing speech sounds. By way of illustration, consider the phonological- and semantic-level nodes that represent the common word skirt during both comprehension and production under TDH. Figure 1 shows a subset of these nodes. For comprehension, phonological nodes in Figure 1 connect bottom-up to a single lexical node that represents the word skirt in the semantic system, and for production, the lexical node representing skirt connects top-down ${ }^{1}$ to these same phonological nodes and to the systems of muscle movement nodes for producing the word skirt aloud (not shown in Figure 1). In addition to these nodes, there is a system of orthographic nodes (not shown in Figure 1) with direct links to lexical nodes and also lateral links to corresponding phonological nodes (necessary for production of novel words and pseudowords; see MacKay \& Abrams, 1998, for a detailed discussion of the TDH orthographic system). What is important to note is the asymmetric structure of top-down versus bottom-up connections in Figure 1: The bottom-up links for identifying the word skirt converge many-to-one onto the lexical node for skirt, whereas the top-down links for producing skirt are one-to-one Only one node primes each phonological node top-down.

Comprehension and production at phonological and lexical levels therefore engage identical nodes and connections, and differences between word comprehension versus word production arise from the asymmetric structure of bottom-up versus top-down connections. Comprehension mainly proceeds bottom-up: Hearing or seeing the word skirt transmits bottom-up priming via many phonological nodes whose connections converge onto a single lexical node. Skirt is then identified as a word when its lexical node is activated as the most primed node in its domain. Activating skirt under this "most-primed-wins" principle allows its identification and comprehension as a word (e.g., in a lexical decision task) and, in turn, transmits priming to connected nodes representing propositions about skirts, and higher level comprehension of skirt occurs when one or more of its propositions is activated.

By contrast, production of the word skirt mainly proceeds topdown: The lexical node for skirt is activated first and transmits priming simultaneously and divergently through the entire hierarchy of phonological nodes representing skirt. Once primed, these phonological nodes and their connected muscle movement nodes become activated one after another in sequence via tree-traversal processes until the entire hierarchy of nodes representing skirt has been successfully activated.

TDH makes predictions for two types of measures common to comprehension and production tasks: error frequencies and production onset times. Error frequencies and production onset times reflect how much priming particular connections transmit (e.g., MacKay, 1987, pp. 25-59), and three factors influence priming transmission under TDH: how recently a node has been activated, how frequently a node has been activated over the life span, and aging (MacKay \& Burke, 1990). Connections between nodes are weaker and transmit less priming with nonrecent activation or a history of infrequent activation over the life span, and connections

\footnotetext{
${ }^{1}$ The use of top-down within the theory encompasses any priming transmission that proceeds from higher level nodes to lower level nodes and thus includes but is not limited to the common use of top-down in cognitive psychology to refer to processes, whereby knowledge or context influences how an input is interpreted.
} 


\section{SEMANTIC SYSTEM}

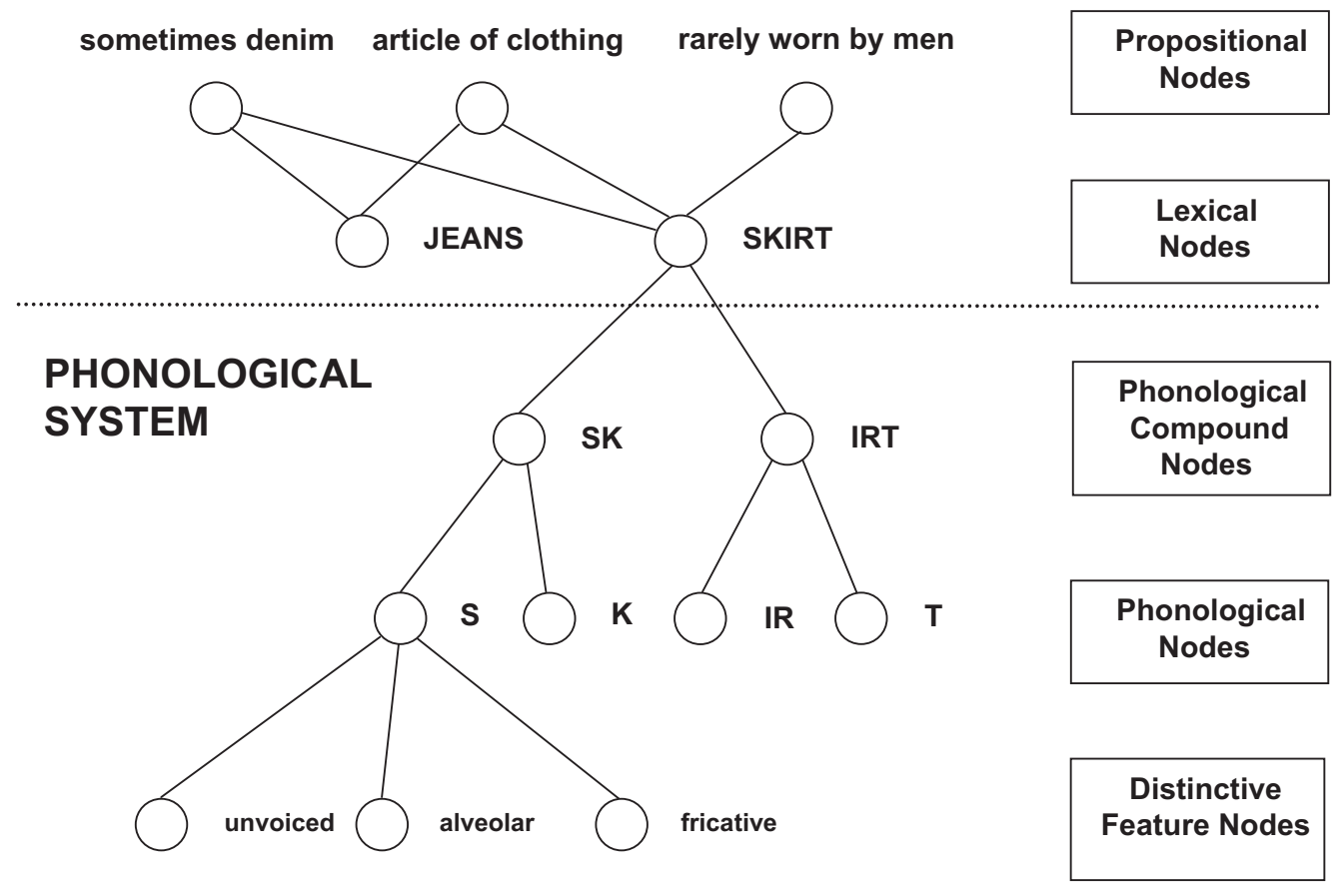

Figure 1. Aspects of the internal representation of skirt in the transmission deficit hypothesis interactive network.

with the same activation history are weaker and transmit less priming for older than for young adults.

Because aging causes a statistical decrease in transmission of priming across connections throughout the entire network, age effects will be greatest when a node critical to a task receives priming from only a single source or connection within the network. If that one connection is defective, then the critical node will be difficult to activate (resulting in more errors and longer production onset times) because no other sources of priming can offset the reduced priming across that connection. For example, a transmission deficit across the top-down link between the lexical node representing the noun skirt and the phonological node representing the consonant cluster/sk/ in Figure 1 would slow down the onset time for producing skirt because no other source of priming could offset the transmission deficit. However, when identifying the word skirt, two bottom-up phonological connections deliver conjoint priming to the lexical node for skirt. Because the resulting summation of priming across these connections will tend to offset an age-linked transmission deficit involving one of these links, the lexical node for skirt will be activated as the most primed lexical node, and skirt will be accurately identified despite the transmission deficit involving/sk/. TDH therefore predicts small or nonexistent age deficits in comprehension at phonological and lexical levels, despite large age deficits for word production. No previous study has tested this prediction for identical participants and identical stimuli in comparably difficult tasks involving comprehension versus production of isolated words.
The Lexical Status and Onset-Output Asymmetries in Production

TDH also predicts special asymmetries for two measures applicable only to production tasks: production onset times and output duration, that is, acoustic duration in the case of producing isolated stimuli. One predicted asymmetry concerns effects of aging on onset times for producing familiar versus novel units. The familiar units of interest here are well-known words with already formed and highly practiced top-down connections: Many familiar words have a lexical node that undergoes a very large number of activations and low-level phonological nodes that undergo an even greater number of activations over the life span. The novel units of interest here are pseudowords with at least one top-down connection having no prior history of activation. For example, unlike the word write, no lexical or syllable node with top-down connections exists for the novel pseudoword wrike. Producing wrike as a monosyllabic unit therefore entails the formation of new top-down connections, a process that requires robust priming for prolonged periods, unlike activation via already formed connections (see MacKay \& Burke, 1990). This prolonged activation process for new connection formation is relatively slow, a slowness reflected in the time between stimulus presentation and production onset in speeded pronunciation tasks: Never previously encountered pseudowords exhibit longer production onset times than familiar words with already formed top-down connections (e.g., MacKay \& James, 2002). Under TDH, this difference in production onset time for words versus pseudowords will be exaggerated in older adults 
because age-linked transmission deficits entail further prolongation of activation when forming top-down connections for producing pseudowords (MacKay \& Burke, 1990). ${ }^{2}$ In short, TDH predicts an age-linked lexical status asymmetry: larger effects of aging on production onset times for pseudowords than for words.

Turning to output duration, words and pseudowords containing similar phonemes (e.g., write vs. wrike) or identical phonemes in different orders (e.g., torn vs. nort) will differ in output duration for both young and older adults under TDH because pseudowords such as wrike and nort are rare or nonexistent as syllables in English. However, lower level phonological constituents of these pseudoword syllables do exist (e.g., the final consonant cluster /rt/, the rhyme or vowel groups /-ike/, and /-ort/, and the segments /r/, /i/, /k/, /n/, /o/, /r/, and /t/) and have had a great deal of prior practice for words and pseudowords containing identical phonemes. Because the activation of already formed low-level nodes is a major determinant of output duration (MacKay \& James, 2002; Santiago, MacKay, Palma, \& Rho, 2000), ${ }^{3}$ the difference in output duration for words versus pseudowords will therefore be small relative to the difference in production onset times under TDH.

Moreover, TDH predicts an age-linked onset-output asymmetry, an Age $\times$ Lexical Status $\times$ Time Measure interaction reflecting greater effects of aging for pseudowords than for words, especially as measured via onset times compared with output durations in the pronunciation task. The reason is that age-linked transmission deficits greatly impact new connection formation, the primary determinant of one time measure (production onset time), but leave intact the process of activating highly practiced low-level nodes, the primary determinant of our other time measure (output duration for words and pseudowords). In other words, older adults will have pronounced difficulty forming new connections to represent pseudowords, and this will lengthen older adults' onset times compared with young adults', but pseudoword output durations will not be impacted to the same extent by older adults' difficulty in new connection formation. In the present study, we tested for this predicted onset-output asymmetry (an Age $\times$ Lexical Status $\times$ Time Measure interaction), which has been examined in no previous studies.

\section{The Present Paradigm: Perception Versus Production of Words and Pseudowords}

To address the issue of artifacts in previous studies in which word comprehension versus production was examined separately, we used exactly the same participants and stimuli in comprehension and production tasks of comparable overall difficulty, as measured post hoc. Participants saw briefly presented words and pseudowords with production instructions ("Produce the stimulus aloud as quickly as possible") versus comprehension instructions ("Indicate as quickly as possible 'yes' if the stimulus is a word or 'no' if not a word"). Processing that could be labeled perceptual, decision, response selection, and response execution is of course involved in both tasks. However, the lexical decision task is primarily a perceptual or input-side task under node structure theory for two reasons. One is that, like perception in general, priming without activation of phonological nodes suffices for activating the lexical node for deciding "word" and executing the response "yes." Moreover, the response execution processes are fixed rather than variable across stimuli in lexical decision tasks.
By contrast, the naming task is primarily a production or outputside task under node structure theory because, like production in general, priming of phonological nodes is insufficient for naming: To produce a word either silently or aloud, its full hierarchy of phonological nodes must be activated in sequence (MacKay, 1987, pp. 111-125). Naming is also primarily a production or output-side task because of the complexity and variability of the response execution processes: Each stimulus in a naming task requires different response execution processes (e.g., Santiago et al., 2000).

The TDH predicted three age-linked asymmetries: an inputoutput asymmetry, reflecting smaller age-linked deficits for onset times and errors during lexical decision than word production; a lexical status asymmetry, reflecting smaller age-linked deficits in onset times to produce words versus never previously encountered pseudowords; and an onset-output asymmetry, reflecting a lexical status asymmetry for onset time but not for output duration during production.

\section{Method}

\section{Participants}

Young $(n=24)$ and healthy older $(n=24)$ adults participated for either $\$ 10$ or extra credit in a psychology course (see Table 1 for background characteristics). All were native speakers of American English.

\section{Materials}

Stimuli were 80 monosyllabic words (e.g., cold, wreck, damp, white, plant) with high frequency $(M=85.6$, in Francis \& Kucera, 1982), and 80 pseudowords (e.g., colp, wreth, dimp, whike, plont) formed by substituting a single phoneme in monosyllabic English words, matched with the words in length $(M=4.2$ letters). Ten additional words and pseudowords served as practice stimuli for the lexical decision and pronunciation tasks.

\section{Procedure}

Because stimuli were counterbalanced across tasks, and task order was counterbalanced across participants, the two tasks involved identical stimuli but different responses: For the lexical decision task, participants said "yes" as quickly as possible if the stimulus was a real English word and "no" otherwise, whereas for the pronunciation task, they pronounced the stimulus aloud as quickly as possible. Instructions for each task were presented verbally and via computer monitor, followed by 20 practice and 80 experimental trials. To initiate each trial, participants pressed a key that triggered a 350-ms fixation point, followed by a stimulus word or pseudoword in large (36-point) font centered on the monitor for

\footnotetext{
${ }^{2}$ Transmission deficits can also increase onset times for activating already formed phonological connections when producing familiar lowfrequency words. To minimize this type of onset time effect, we only included high-frequency words in the present experiment.

${ }^{3}$ As noted by MacKay and James (2002, Footnote 7, p. 314), we cannot rule out the possibility that some connection formation occurs following production onset and may influence output duration. However, the impact of new connection formation is predicted to be much greater on onset times than on pronunciation durations.
} 
Table 1

Means and Standard Deviations of Participant Characteristics

\begin{tabular}{|c|c|c|c|c|}
\hline \multirow[b]{2}{*}{ Variable } & \multicolumn{2}{|c|}{ Young adults } & \multicolumn{2}{|c|}{ Older adults } \\
\hline & $M$ & $S D$ & $M$ & $S D$ \\
\hline Age in years & 24.04 & 4.54 & 73.58 & 5.36 \\
\hline $\begin{array}{l}\text { Nelson-Denny vocabulary } \\
\text { test score } \text { (maximum }^{\text {a }} \\
=25 ; \text { J. I. Brown, } \\
1960 \text { ) }\end{array}$ & 14.54 & 3.44 & 18.91 & 352 \\
\hline Years of education ${ }^{\mathrm{b}}$ & $\begin{array}{l}14.04 \\
15.79\end{array}$ & $\begin{array}{l}5.44 \\
1.35\end{array}$ & 15.13 & 2.18 \\
\hline
\end{tabular}

${ }^{\mathrm{a}}$ This age difference was significant, $t(45)=4.31, p<.01{ }^{\mathrm{b}}$ This age difference was not significant $(p>.21)$.

$1,000 \mathrm{~ms}$. Sessions were audiotaped to subsequently check the online scoring of errors and to measure onset time and acoustic duration for each response from waveforms digitized via SoundEdit 16 (which is now discontinued; Macromedia).

\section{Results}

Invalid trials, in which participants failed to respond or reported not seeing the stimulus, did not differ by age (young $M=0.10 \%$, $S D=0.51 \%$; older $M=0.31 \%, S D=0.67 \%, p>.22)$ and were removed before all analyses.

\section{Error Analyses}

For production, we accepted only one correct pronunciation for words but two phonologically plausible pronunciations for some pseudowords (e.g., "yeft" and "yeeft" for the pseudoword yeaft). We scored errors using two criteria: a lenient criterion that included fluency problems (e.g., "uh carm" and "yyyyyes") and corrected errors (e.g., "wrap- no, wrab" and "y- no") and a strict criterion that excluded both. These scoring criteria yielded very similar results, ruling out fluency and correction problems as the basis for present age effects. In the interest of including as many data points as possible for follow-up analyses, we report analyses on the basis of lenient data scoring for the analyses involving errors (see Table 2 and Figure 2).

Table 2 presents mean correct responses as percentage of valid trials. A 2 (age group: young, older) $\times 2$ (task: pronunciation,

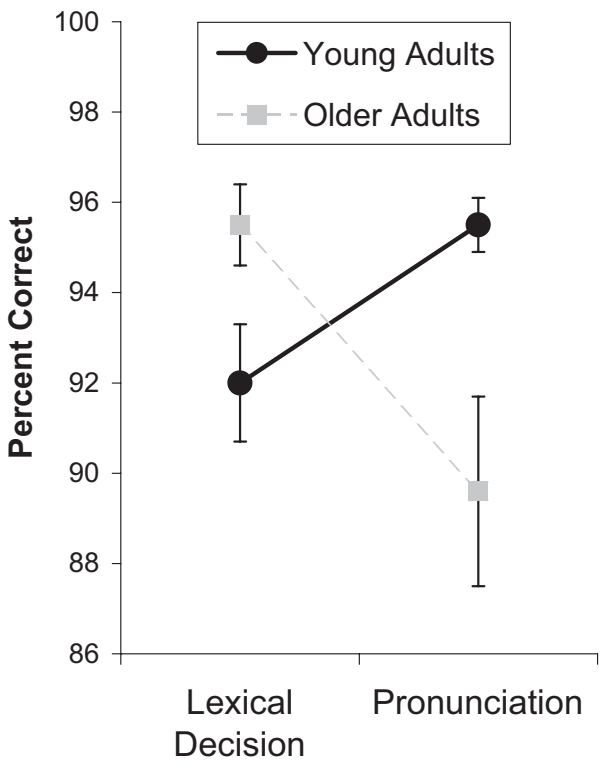

Figure 2. Mean percentage correct as a function of task and age group under lenient scoring criteria. Error bars represent \pm 1 standard error.

lexical decision) $\times 2$ (lexical status: words, pseudowords) mixed analysis of variance (ANOVA) on these data yielded no main effect of age (young $M=94 \%, S D=4 \%$; older $M=93 \%, S D=$ $7 \%, p>.45$ ) or task (lexical decision $M=94 \%, S D=6 \%$; pronunciation $M=93 \%, S D=8 \%, p>.23$ ), indicating that the present perception and production tasks were comparable in overall error-related difficulty for young and older adults. However, there was a crossover Age $\times$ Task interaction, $F(1,46)=24.03$, $M S E=.004, p<.01$. Follow-up tests indicated reliably better performance for young $(M=96 \%, S D=3 \%)$ than for older adults $(M=90 \%, S D=10 \%)$ on the pronunciation task, $F(1,46)=7.99$, $M S E=.010, p<.01$, but reliably better performance for older $(M=95 \%, S D=4 \%)$ than for young adults $(M=92 \%, S D=$ $6 \%)$ on the lexical decision task, $F(1,46)=4.71, M S E=.006$, $p<.05$. Our strict scoring criterion yielded this same crossover interaction with scores further from ceiling, $F(1,46)=19.32$, $M S E=.011, p<.01$.

The ANOVA on leniently scored data yielded a main effect of lexical status, $F(1,46)=49.35, M S E=.007, p<.01$, with better

Table 2

Means and Standard Deviations of Accuracy (Lenient Percentage Correct), Response Onset Time, and Response Output Duration (Pronunciation Task Only) for Young and Older Adults by Task and Lexical Status

\begin{tabular}{|c|c|c|c|c|c|c|c|c|c|c|c|c|c|c|c|c|}
\hline \multirow[b]{4}{*}{ Variable } & \multicolumn{8}{|c|}{ Young adults } & \multicolumn{8}{|c|}{ Older adults } \\
\hline & \multicolumn{4}{|c|}{ Lexical decision } & \multicolumn{4}{|c|}{ Pronunciation } & \multicolumn{4}{|c|}{ Lexical decision } & \multicolumn{4}{|c|}{ Pronunciation } \\
\hline & \multicolumn{2}{|c|}{ Words } & \multicolumn{2}{|c|}{ Pseudowords } & \multicolumn{2}{|c|}{ Words } & \multicolumn{2}{|c|}{ Pseudowords } & \multicolumn{2}{|c|}{ Words } & \multicolumn{2}{|c|}{ Pseudowords } & \multicolumn{2}{|c|}{ Words } & \multicolumn{2}{|c|}{ Pseudowords } \\
\hline & $M$ & $S D$ & $M$ & $S D$ & $M$ & $S D$ & $M$ & $S D$ & $M$ & $S D$ & $M$ & $S D$ & $M$ & $S D$ & $M$ & $S D$ \\
\hline Percentage correct & 95.00 & 5.47 & 88.96 & 12.64 & 99.06 & 1.93 & 91.97 & 5.42 & 98.23 & 2.50 & 92.71 & 8.04 & 97.80 & 4.02 & 81.42 & 16.19 \\
\hline Response onset time & 670 & 129 & 843 & 234 & 521 & 86 & 594 & 116 & 778 & 186 & 943 & 275 & 590 & 122 & 731 & 191 \\
\hline Response output duration & & & & & 475 & 66 & 482 & 64 & & & & & 538 & 74 & 554 & 80 \\
\hline
\end{tabular}

Note. Response onset time and response output duration appear in milliseconds. 
overall performance on words $(M=98 \%, S D=3 \%)$ than pseudowords $(M=89 \%, S D=10 \%)$. However, this main effect was qualified by a Task $\times$ Lexical Status interaction, $F(1,46)=$ 9.57, MSE $=.004, p<.01$, and an Age $\times$ Task $\times$ Lexical Status interaction, $F(1,46)=6.49, M S E=.004, p<.05$. Because these interactions marked lexical status as an important variable in our age and task effects, we next computed separate 2 (age group: young, older) $\times 2$ (lexical status: words, pseudowords) ANOVAs for the pronunciation versus lexical decision tasks. The lexical decision ANOVA yielded a main effect of age (young $M=92 \%$, $S D=6 \%$; older $M=95 \%, S D=4 \%), F(1,46)=4.71, M S E=$ $.006, p<.05$, but no Age $\times$ Lexical Status interaction $(F<1)$. However, the pronunciation ANOVA yielded a reliable Age $\times$ Lexical Status interaction, $F(1,46)=10.17, M S E=.005$, $p<.01$, reflecting no age difference for words (young $M=99 \%$, $S D=2 \%$; older $M=98 \%, S D=4 \%, p>.17$ ) but an age difference for pseudowords (young $M=92 \%, S D=5 \%$; older $M=81 \%, S D=16 \%), t(46)=3.03, p<.01$, with fewer errors for young than for older adults (see Figure 3, left panel). To eliminate possible ceiling effects, we also performed separate median splits on the basis of overall performance of young and older adults and reanalyzed the percentage of correct data for participants with below-median performance in a 2 (age group: young, older) $\times 2$ (lexical status: words, pseudowords) mixed ANOVA. This ANOVA yielded the same Age $\times$ Lexical Status interaction, $F(1,18)=31.03, M S E=.003, p<.01$, reflecting a reliable age difference for pseudowords (young $M=86 \%, S D=$ $3 \%$; older $M=65 \%, S D=13 \%), t(18)=4.34, p<.01$, but not for words (young $M=97 \%, S D=2 \%$; older $M=96 \%, S D=5 \%$, $p>$.33). This replication rules out ceiling effects as the basis for the interaction in our main analysis.

We compared percentage of correct pronunciation for pseudowords with two acceptable pronunciations $(n=12)$ versus one acceptable pronunciation $(n=68)$ in a 2 (age group: young, older) $\times 2$ (acceptability: one vs. two pronunciations) ANOVA. No main effect of acceptability (one pronunciation $M=87 \%$, $S D=11 \%$; two pronunciations $M=88 \%, S D=11 \%, F<1)$, and no Acceptability $\times$ Age interaction $(p>.28)$ emerged, indicating that pseudowords with one versus two acceptable pronunciations did not differ in ease of pronunciation and that our scoring procedures did not favor one age group over the other.

Because education level was slightly (although nonsignificantly) higher for young than for older adults, and vocabulary scores were significantly higher for older than for young adults (see Table 1), we correlated years of education and vocabulary score with percentage correct in each task for all participants (as well as separately for young and older participants). All correlations were either unreliable or inconsistent with education and vocabulary as causes of obtained age differences and were not pursued further.

\section{Onset Time Analyses}

We analyzed mean onset times for strictly correct responses in a 2 (age group: young, older) $\times 2$ (task: pronunciation, lexical decision) $\times 2$ (lexical status: words, pseudowords) mixed

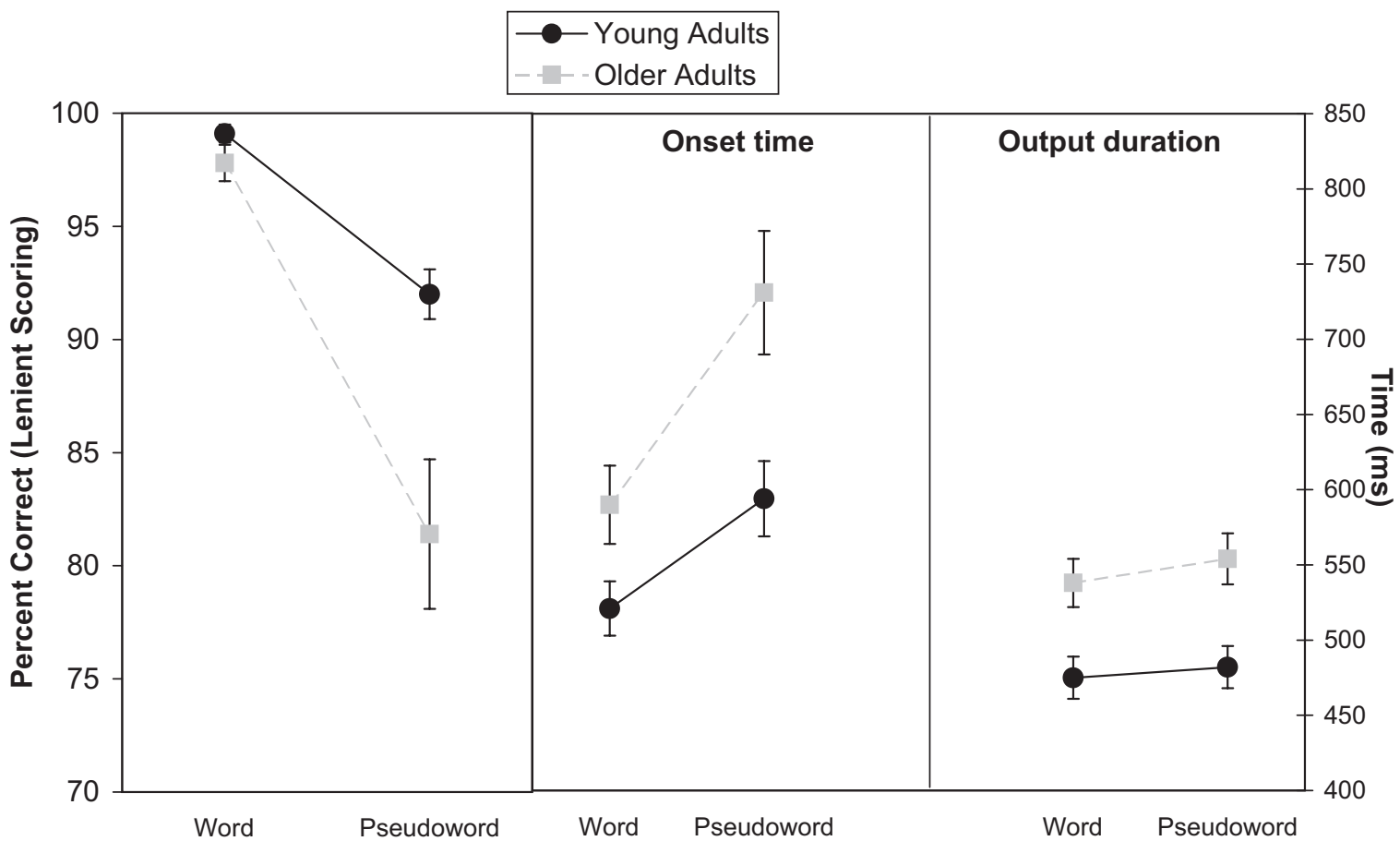

Figure 3. Mean percentage correct (lenient scoring; left panel), mean correct onset time (middle panel), and mean correct pronunciation duration (right panel) as a function of age group and lexical status in the production task. Error bars represent \pm 1 standard error. 
ANOVA that yielded three main effects (see Table 2): ${ }^{4}$ lexical status, $F(1,42)=93.08, M S E=9,006, p<.01$, with faster onset times for words $(M=640, S D=131)$ than pseudowords $(M=$ $778, S D=200)$; age, $F(1,42)=4.91, M S E=96,203, p<.05$, with faster onset times for young $(M=657, S D=120)$ than for older adults $(M=755, S D=167)$; and task, $F(1,42)=95.11$, $M S E=18,352, p<.01$, with faster onset times for pronunciation $(M=607, S D=125)$ than for lexical decision $(M=805, S D=$ $199)$, indicating that the present comprehension task was at least as difficult as the production task.

The age difference was significant for pronunciation (young $M=$ $562, S D=100$; older $M=651, S D=133), t(42)=2.50, p<.05$, and approached significance for lexical decisions (young $M=751$, $S D=164$; older $M=859, S D=219), t(42)=1.84, p=.07$, although the Age $\times$ Task interaction did not approach significance $(F<1)$. However, there was an Age $\times$ Task $\times$ Lexical Status interaction, $F(1,42)=4.65, M S E=3,552, p<.05$, that called for separate 2 (age group: young, older) $\times 2$ (lexical status: words, pseudowords) ANOVAs for the two tasks. The lexical decision ANOVA yielded no Age $\times$ Lexical Status interaction $(F<1)$, whereas the pronunciation task did, $F(1,42)=9.39, M S E=2,807$, $p<.01$, because of a large age difference favoring young adults for pseudowords $(M=594, S D=116$; older $M=731, S D=191)$, $t(42)=2.88, p<.01$, but a smaller age difference for words (young $M=521, S D=86$; older $M=590, S D=122), t(42)=2.15, p<$ .05 (see Figure 3, middle panel).

As with percentage correct, we correlated years of education and vocabulary scores with onset times for each task for all participants (as well as separately for young and older participants). Again, all correlations were unreliable or inconsistent with education and vocabulary as causes of obtained age differences and were not pursued further.

Three additional onset time analyses indicated that speed-accuracy trade-off was not the basis for the age differences in pronunciation errors noted earlier. First, young adults produced fewer errors but were not slower to initiate correct responses than older adults. Second, response onset times were longer for errors than correct responses, contrary to speed-accuracy trade-off. For the 16 participants ( 7 young and 9 older) who made errors in pronouncing words, a paired $t$ test indicated longer onset times for incorrect $(M=805, S D=379)$ than correct responses $(M=563, S D=163), t(15)=3.77, p<.01$. For the 41 participants (20 young and 21 older) who made errors in pronouncing pseudowords, a paired $t$ test likewise indicated longer onset times for incorrect $(M=751, S D=207)$ than correct responses $(M=667, S D=175), t(40)=3.69, p<.01$. Third, correlations between mean percentage correct and mean correct onset time in the pronunciation task were either low and unreliable or inconsistent with speed-accuracy trade-off. For young adults, the correlation between percentage correct and onset time for words was .06 $(p>.79)$ and for pseudowords was $-.23(p>.29)$. For older adults, the correlation between percentage correct and onset time for words was .05 ( $p>$ $.83)$ and for pseudowords was $-.70(p<.01)$, a reliable negative correlation inconsistent with speed-accuracy trade-off.

\section{Onset Time Versus Output Duration Comparisons}

TDH predicted an onset-output asymmetry, reflecting a larger age-linked lexical status effect for onset times than for output duration, the acoustic duration of correctly produced stimuli in the pronunciation task. To test for this onset-output asymmetry, we compared mean correct onset times (see Figure 3, middle panel) with mean correct output durations (see Figure 3, right panel) as a function of age group and lexical status (see also Table 2). A 2 (age group: young, older) $\times 2$ (lexical status: words, pseudowords $) \times$ 2 (time measure: production onset, output duration) mixed ANOVA yielded an Age $\times$ Lexical Status $\times$ Time Measure interaction, $F(1,42)=8.28, M S E=1,186, p<.01$, that called for separate 2 (age group: young, older) $\times 2$ (lexical status: words, pseudowords) ANOVAs for each time measure. The production onset time ANOVA yielded the main effects and Age $\times$ Lexical Status interaction noted earlier, reflecting an age-linked lexical status asymmetry. The output duration ANOVA yielded a main effect of age (young $M=478, S D=65$; older $M=546, S D=$ 76), $F(1,42)=10.20, M S E=9,869, p<.01$, and of lexical status (words $M=507, S D=76$; pseudowords $M=518, S D=81$ ), $F(1$, $42)=7.24, M S E=355, p<.05$, but no Age $\times$ Lexical Status interaction $(p>.24)$, indicating no age-linked lexical status asymmetry for output duration.

\section{Discussion}

Present age-linked deficits can be characterized as selective rather than across-the-board: Errors were greater for older than for young adults in production but not comprehension, the age difference for onset times was greater in production than in comprehension, and greater in producing pseudowords but not words, but effects of aging on output duration were no greater for producing pseudowords than words. Present results therefore add to numerous other demonstrations of selective rather than across-the-board age-linked deficits in phonological and lexical-level processing. To illustrate one recent demonstration, consider the impact of aging on experimentally induced phonological speech errors in MacKay and James (2004): Compared with young adults, phonological speech errors of older adults contained relatively more omissions and order errors but relatively fewer substitutions of correctly ordered speech sounds. This age-linked error-type asymmetry indicates another selective rather than across-the-board effect of aging at phonological levels. Such selective effects challenge theories of cognitive aging to explain why some aspects of information processing are more vulnerable to age-linked impairment than others.

Present results also extend input-output asymmetries demonstrated in other studies. For example, Ober, Shenaut, Jagust, and Stillman (1991) reported larger age-linked deficits for onset times in pronunciation than lexical decision with stimuli randomly selected from a pool, and the present results extend this pattern to errors using identical stimuli in the two tasks. Present results also extend input-output asymmetries demonstrated for orthographic information in MacKay, Abrams, and Pedroza (1999), the only other published study with identical stimuli and participants and equally difficult production versus comprehension tasks. In the comprehension task, older adults identified briefly presented words as correctly or incorrectly spelled at least as often as young adults. However, in the production task, young adults correctly

\footnotetext{
${ }^{4}$ Because of tape recording problems, response times for 2 young and 2 older participants were unavailable, as the degrees of freedom indicate.
} 
retrieved the just seen (mis)spellings more often than older adults, an age-linked deficit in spelling production that comports with other findings (e.g., MacKay \& Abrams, 1998; Stuart-Hamilton \& Rabbitt, 1997). The differing effects of aging on comprehension versus production of orthography indicate an age-linked inputoutput asymmetry such that, other factors being equal, comprehension of orthographic units remains constant with aging, whereas production of the same orthographic units exhibits agelinked declines. In short, input-output asymmetries have now been demonstrated at three levels of language processing: orthographic, phonological, and lexical.

The input-output asymmetry we identified (i.e., age-linked deficits for onset times and errors in producing words and pseudowords but not in identifying the same stimuli as words vs. nonwords) comports with the TDH framework of MacKay and Burke (1990): Comprehension and production are not mirror image processes, and aging has disproportionately greater effects on production than on comprehension. The TDH explains inputoutput asymmetries as the result of the differing structure of top-down versus bottom-up connections. Age effects are greatest under TDH when a node critical to a task receives priming from only a single source or connection within the network, a "single source condition" that applies to the top-down connections for retrieving phonology (see Figure 1) and orthography (see MacKay \& Abrams, 1998; MacKay et al., 1999). Age-linked deficits on the output side in these and other studies therefore comport with TDH.

Turning to the input side, age effects are small or nonexistent under TDH when a node critical to a task receives priming simultaneously from more than one source or connection within the network, a "multiple source condition" that applies to the bottom-up connections for identifying familiar words at phonological and lexical levels (see Figure 1). The age constancy in identifying words as words and pseudowords as nonwords in the present experiment and other studies noted earlier therefore comport with TDH.

We now consider three unlikely accounts of our input-output asymmetry. One is the two-factor theory of Salthouse (1996), in which one factor (general slowing) degrades cognitive performance of older adults because a second factor (forgetting or unavailability of information) eliminates the products of earlier processing at the time when later processing requires those products. A key variable in two-factor theory is task complexity. Two-factor theory predicts more errors and longer response times with more complex tasks, especially for older adults. The reason is that complex tasks involve more underlying operations than simple tasks, and older adults are more likely than young adults to forget the processing products of those additional underlying operations because of delays caused by age-linked slowing. Two-factor theory can therefore explain input-output asymmetries under the assumption that production tasks are inherently more complex than perception tasks. However, contrary to a complexity account of our input-output asymmetry, young adults had faster onset times for production than for comprehension, and they made fewer errors during production than comprehension (see Figure 2), which suggests that, independent of the age factor, the present comprehension task was at least as difficult as the production task. ${ }^{5}$

The second unlikely account of our input-output asymmetry derives from an inhibitory deficit hypothesis, whereby older adults are less able than young adults to suppress or inhibit related but currently irrelevant concepts, including phonologically similar words (see, e.g., Hasher \& Zacks, 1988; Zacks \& Hasher, 1997). Thus, if the pseudoword stimulus plont triggers the irrelevant concept plant, then suppression of plant would be more difficult for older than for young adults, interfering with production onset for plont under this inhibitory deficit hypothesis. However, this same age-linked difficulty in suppressing plant should also occur in deciding whether plont is a real word so that this inhibitory deficit hypothesis fails to explain why our comprehension and production tasks did not exhibit interference effects of comparable magnitude.

The third unlikely account of our input-output asymmetry comes from theories that attribute cognitive aging to an acrossthe-board factor such as general slowing (e.g., Myerson et al., 1990) and view perception and production as mirror image processes. Such theories cannot predict age-linked input-output asymmetries and can only explain the present results as artifactual.

However, we have already discussed and ruled out artifacts related to ceiling effects, floor effects, and task difficulty, and the methodology of the present experiment also rules out artifacts related to the power in our design, age-linked sensory deficits, cohort differences, task-linked orthographic-phonological correspondence effects, and stimulus differences. Contrary to the hypothesis that our input-output asymmetry reflected insufficient power to detect age differences in the present comprehension task, our design carried more than enough power to detect the opposite direction of age difference in this task: Older adults made fewer errors than young adults during lexical decision. The form of our input-output asymmetry also ruled out sensory-level artifacts in the asymmetric effects of aging on the input versus output side: Age-linked sensory deficits could only increase the frequency of misperceptions and lexical decision errors for older relative to young adults, contrary to present results. Cohort differences related to education level likewise cannot explain the present agelinked production deficits: Education level was very similar for young and older adults (see Table 1), and years of education were not significantly correlated with production errors for either young or older adults. Nor can task-linked effects of orthography-tophonology correspondence explain the present age-linked production deficits. Although regular orthography-to-phonology correspondence rules are potentially important for pronouncing lowfrequency words, we only used high-frequency words, for which this is not the case (see, e.g., Balota \& Ferraro, 1993; Seidenberg, Waters, Barnes, \& Tanenhaus, 1984). Moreover, the present inputoutput asymmetry remained intact following removal of the relatively rare trials in which participants pronounced pseudowords via irregular orthography-to-phonology correspondence rules, and the present stimuli were identical (across participants) in the lexical decision and pronunciation tasks, controlling for orthography-

\footnotetext{
${ }^{5}$ Like Balota and Chumbley (1984), we assume that onset times are longer in lexical decision than in naming tasks because of the fundamentally different decision processes in the two tasks. For lexical decision tasks, the decision is context dependent because the nature of the nonwords can determine onset times for responding "word" as well as "nonword." By contrast, deciding to produce a word is a highly practiced process, occurring each time a word is produced over the course of a lifetime, and an invariant process across stimuli in a naming task.
} 
to-phonology correspondence across tasks. Finally, use of identical participants as well as stimuli in the present study ruled out sources of artifact that may have contributed to the age-linked asymmetries in previous studies that separately examined comprehension versus production of lexical and phonological information. In short, present results suggest that the age-linked input-output asymmetry is fundamental rather then artifactual and challenge theories of cognitive aging to explain why aging impairs output-side processing more than input-side processing.

Like the input-output asymmetry, the lexical status asymmetry (i.e., smaller age-linked deficits in errors and onset times to produce familiar words versus never previously encountered pseudowords) is neither artifactual nor readily explained in theories in which cognitive aging reflects a single factor such as general slowing (e.g., Myerson et al., 1990). General slowing may explain our main effect of aging on response times for words and pseudowords but not our age-linked interaction with lexical status. A dual-route theory of reading aloud (e.g., Coltheart, Rastle, Perry, Langdon, \& Ziegler, 2001) could account for the lexical status effect in production by assuming that our pseudoword stimuli must be processed via the slow, assembled route to achieve accurate production, whereas our high-frequency, regularly spelled word stimuli are processed via the quick, addressed route and are therefore more quickly produced. However, these assumptions do not provide a complete account for several aspects of our data, for example, the relatively high rate of pseudoword pronunciation errors and the occurrence of a variety of error types (including many nonregularization errors) in producing pseudowords. However, TDH readily accounts for the lexical status asymmetry for both response onset times and errors, while simultaneously explaining many other obtained results. Under TDH, age-linked reductions in the transmission of priming especially impact the process of forming new connections. Because new connections are required to represent and produce never previously encountered pseudowords, the smaller age-linked deficits for producing pseudowords versus words with already formed connections reflects the same general processes that cause age-linked deficits in new learning under TDH (see MacKay \& Burke, 1990, for a review).

As in Balota and Duchek (1988), aging increased overall output duration for stimuli in the present study, indicating that output duration is not immune to age effects. So why did aging interact with lexical status for onset times but not for output durations? The obtained onset-output asymmetry is difficult to explain under theories in which cognitive aging reflects a single factor such as general slowing (e.g., Myerson et al., 1990). General slowing may explain our main effect of aging on output duration for words and pseudowords but not our Age $\times$ Lexical Status $\times$ Time Measure interaction. However, TDH readily accounts for this onset-output asymmetry. New connections are required to represent and produce pseudowords but not words, and the process of forming new connections impacts onset times to a greater extent than output durations. The reason is that onset time primarily reflects outputside planning processes, whereby new connections are formed prior to production. By contrast, output duration primarily reflects activation processes involving already formed low-level connections with asymptotic levels of prior practice for both words and pseudowords. Because aging impacts new connection formation but not the process of activating highly practiced nodes under
TDH, age-linked transmission deficits impact onset times much more than output durations for words versus pseudowords containing similar or identical phonemes.

Present results supported three age-linked asymmetries: an input-output asymmetry for identifying versus producing phonological information (i.e., age-linked deficits for onset times and errors in producing words vs. pseudowords but not in identifying the same stimuli as words vs. nonwords); a lexical status asymmetry (i.e., large age-linked deficits for onset times and errors in producing pseudowords but not words); and an onset-output asymmetry (i.e., an age-linked lexical status asymmetry for onset times but not output durations). All three asymmetries supported predictions of TDH but contradict theories that predict either sparing or impairment of verbal abilities across the board and cannot explain why some aspects of information processing are more vulnerable to effects of aging than others.

\section{References}

Au, R., Joung, P., Nicholas, M., Obler, L. K., Kass, R., \& Albert, M. L. (1995). Naming ability across the adult life span. Aging and Cognition, 2, 300-311.

Balota, D. A., \& Chumbley, J. I. (1984). Are lexical decisions a good measure of lexical access? The role of word frequency in the neglected decision stage. Journal of Experimental Psychology: Human Perception and Performance, 3, 340-357.

Balota, D. A., \& Duchek, J. M. (1988). Age-related differences in lexical access, spreading activation, and simple pronunciation. Psychology and Aging, 3, 84-93.

Balota, D. A., \& Ferraro, F. R. (1993). A dissociation of frequency and regularity effects in pronunciation performance across young adults, older adults, and individuals with senile dementia of the Alzheimer type. Journal of Memory and Language, 32, 573-592.

Botwinick, J. (1984). Aging and behavior. New York: Springer.

Bowles, N. L., \& Poon, L. W. (1985). Aging and retrieval of words in semantic memory. Journal of Gerontology, 40, 71-77.

Brown, A. S., \& Nix, L. A. (1996). Age-related changes in the tip-of-thetongue experience. American Journal of Psychology, 109, 79-91.

Brown, J. I. (1960). The Nelson-Denny reading test. Boston: Houghton Mifflin.

Burke, D. M., \& MacKay, D. G. (1997). Memory, language, and ageing. Philosophical Transactions of the Royal Society of London B, 352, 1845-1856.

Burke, D. M., MacKay, D. G., \& James, L. E. (2000). Theoretical approaches to language and aging. In T. J. Perfect \& E. A. Maylor (Eds.), Models of cognitive aging (pp. 204-237). Oxford, England: Oxford University Press.

Burke, D. M., MacKay, D. G., Worthley, J. S., \& Wade, E. (1991). On the tip of the tongue: What causes word finding failures in young and older adults? Journal of Memory and Language, 30, 542-579.

Burke, D. M., \& Yee, P. L. (1984). Semantic priming during sentence processing by young and older adults. Developmental Psychology, 20, 903-910.

Cohen, G., \& Faulkner, D. (1983). Word recognition: Age differences in contextual facilitation effects. British Journal of Psychology, 74, 239251.

Cohen, G., \& Faulkner, D. (1986). Memory for proper names: Age differences in retrieval. British Journal of Developmental Psychology, 4, 187-197.

Coltheart, M., Rastle, K., Perry, C., Langdon, R., \& Ziegler, J. (2001). DRC: A dual route cascaded model of visual word recognition and reading aloud. Psychological Review, 108, 204-256.

Ferraro, F. R., \& Moody, J. (1996). Consistent and inconsistent perfor- 
mance in young and elderly adults. Developmental Neuropsychology, 12, 429-441.

Feyereisen, P. (1997). A meta-analytic procedure shows an age-related decline in picture naming: Comments on Goulet, Ska, and Kahn (1994). Journal of Speech, Language and Hearing Research, 40, 1328-1333.

Francis, W. N., \& Kucera, H. (1982). Frequency analysis of English usage: Lexicon and grammar. Boston: Houghton Mifflin.

Hasher, L., \& Zacks, R. T. (1988). Working memory, comprehension, and aging: A review and a new view. In G. H. Bower (Ed.), The psychology of learning and motivation (Vol. 22, pp. 193-225). San Diego, CA: Academic Press.

Heine, M. K., Ober, B. A., \& Shenaut, G. K. (1999). Naturally occurring and experimentally induced tip-of-the-tongue experiences in three adult age groups. Psychology and Aging, 14, 445-457.

James, L. E., \& Burke, D. M. (2000). Phonological priming effects on word retrieval and tip-of-the-tongue experiences in young and older adults. Journal of Experimental Psychology: Learning, Memory, and Cognition, 26, 1378-1391.

Kemper, S. (1992). Adults' sentence fragments: Who, what, when, where, and why. Communication Research, 19, 444-458.

Kramer, N. A., \& Jarvik, L. F. (1979). Assessment of intellectual changes in the elderly. In A. Raskin \& L. F. Jarvik (Eds.), Psychiatric symptoms and cognitive loss in the elderly (pp. 221-271). Washington, DC: Hemisphere Publishing.

Laver, G. D. (2000). A speed-accuracy analysis of word recognition in young and older adults. Psychology and Aging, 15, 705-709.

Laver, G. D., \& Burke, D. M. (1993). Why do semantic priming effects increase in old age? A meta-analysis. Psychology and Aging, 8, 34-43.

Light, L. L. (1992). The organization of memory in old age. In F. I. M. Craik \& T. A. Salthouse (Eds.), The handbook of aging and cognition (pp. 111-165). Hillsdale, NJ: Erlbaum.

Light, L. L., Valencia-Laver, D., \& Zavis, D. (1991). Instantiation of general terms in young and older adults. Psychology and Aging, 6, 337-351.

MacKay, D. G. (1987). The organization of perception and action: A theory for language and other cognitive skills. New York: SpringerVerlag.

MacKay, D. G., \& Abrams, L. (1996). Language, memory, and aging: Distributed deficits and the structure of new-versus-old connections. In J. E. Birren \& W. K. Schaie (Eds.), Handbook of the psychology of aging (4th ed., pp. 251-265). San Diego, CA: Academic Press.

MacKay, D. G., \& Abrams, L. (1998). Age-linked declines in retrieving orthographic knowledge: Empirical, practical, and theoretical implications. Psychology and Aging, 13, 647-662.

MacKay, D. G., Abrams, L., \& Pedroza, M. J. (1999). Aging on the input versus output side: Theoretical implications of age-linked asymmetries between detecting versus retrieving orthographic information. Psychology and Aging, 14, 3-17.

MacKay, D. G., \& Burke, D. M. (1990). Cognition and aging: A theory of new learning and the use of old connections. In T. M. Hess (Ed.), Aging and cognition: Knowledge organization and utilization (pp. 213-263). Amsterdam: North-Holland.

MacKay, D. G., \& James, L. E. (2002). Aging, retrograde amnesia, and the binding problem for phonology and orthography: A longitudinal study of "hippocampal amnesic" H. M. Aging, Neuropsychology, and Cognition, 9, 298-333.

MacKay, D. G., \& James, L. E. (2004). Sequencing, speech production, and selective effects of aging on phonological and morphological speech errors. Psychology and Aging, 19, 93-110.

Madden, D. J. (1988). Adult age differences in the effects of sentence context and stimulus degradation during visual word recognition. Psychology and Aging, 3, 167-172.

Maylor, E. A. (1990). Age, blocking and the tip of the tongue state. British Journal of Psychology, 81, 123-134.

McCrae, R. R., Arenberg, D., \& Costa, P. T. (1987). Declines in divergent thinking with age: Cross-sectional, longitudinal, and cross-sequential analyses. Psychology and Aging, 2, 130-137.

Mitchell, D. B. (1989). How many memory systems? Evidence from aging. Journal of Experimental Psychology: Learning, Memory, and Cognition, 15, 31-49.

Myerson, J., Hale, S., Wagstaff, D., Poon, L. W., \& Smith, G. A. (1990) The information-loss model: A mathematical theory of age-related cognitive slowing. Psychological Review, 97, 475-487.

Ober, B. A., Shenaut, G. K., Jagust, W. J., \& Stillman, R. C. (1991). Automatic semantic priming with various category relations in Alzheimer's disease and normal aging. Psychology and Aging, 6, 647-660.

Rastle, K. G., \& Burke, D. M. (1996). Priming the tip of the tongue: Effects of prior processing on word retrieval in young and older adults. Journal of Memory and Language, 35, 586-605.

Salthouse, T. A. (1996). The processing-speed theory of adult age differences in cognition. Psychological Review, 103, 403-428.

Santiago, J., MacKay, D. G., Palma, A., \& Rho, C. (2000). Sequential activation processes in producing words and syllables: Evidence from picture naming. Language and Cognitive Processes, 15, 1-44.

Schmitter-Edgecombe, M., Vesneski, M., \& Jones, D. W. R. (2000). Aging and word finding: A comparison of spontaneous and constrained naming tests. Archives of Clinical Neuropsychology, 15, 479-493.

Seidenberg, M. S., Waters, G. S., Barnes, M. A., \& Tanenhaus, M. K. (1984). When does irregular spelling or pronunciation influence word recognition? Journal of Verbal Learning and Verbal Behavior, 23, 383-404.

Speranza, F., Daneman, M., \& Schneider, B. A. (2000). How aging affects reading of words in noisy backgrounds. Psychology and Aging, 15, $253-258$.

Stine, E. A. L., \& Wingfield, A. (1994). Older adults can inhibit highprobability competitors in speech recognition. Aging and Cognition, 1, $152-157$.

Stuart-Hamilton, I., \& Rabbitt, P. (1997). Age-related decline in spelling ability: A link with fluid intelligence? Educational Gerontology, 23 437-441.

Sunderland, A., Watts, K., Baddeley, A. D., \& Harris, J. E. (1986). Subjective memory assessment and test performance in elderly adults. Journal of Gerontology, 41, 376-384.

Verhaeghen, P. (2003). Aging and vocabulary scores: A meta-analysis. Psychology and Aging, 18, 332-339.

White, K. K., \& Abrams, L. (2002). Does priming specific syllables during tip-of-the-tongue states facilitate word retrieval in older adults? Psychology and Aging, 17, 226-235.

Wingfield, A., Alexander, A. H., \& Cavigelli, S. (1994). Does memory constrain utilization of top-down information in spoken word recognition? Evidence from normal aging. Language and Speech, 37, 221-235.

Wingfield, A., \& Stine-Morrow, E. A. L. (2000). Language and speech. In F. I. M. Craik \& T. A. Salthouse (Eds.), The handbook of aging and cognition (2nd ed., pp. 359-416). Mahwah, NJ: Erlbaum.

Zacks, R. T., \& Hasher, L. (1997). Cognitive gerontology and attentional inhibition: A reply to Burke and McDowd. Journal of Gerontology, Series B: Psychological Sciences and Social Sciences, 52, P274-P283.

Received December 6, 2005

Revision received October 4, 2006

Accepted October 16, 2006 